\title{
SIMULASI DAN MONITORING KOORDINASI RECLOSER DAN SSO PADA JARINGAN DISTRIBUSI 20 KV PT. PLN (PERSERO) AREA SEMARANG PENYULANG KALISARI 07 BERBASIS ARDUINO MEGA 2560 DAN VT SCADA 11.2
}

\author{
Hanif Zuraida, Heru Winarno \\ Program Studi D-III Teknik Elektro, Sekolah Vokasi, Universitas Diponegoro \\ Jl. Prof. Soedarto, SH, Kampus Undip Tembalang, Semarang, Indonesia 50275
}

\begin{abstract}
Hanif Zuraida, Heru Winarno, in this article describes the simulation of protection equipment coordination systems, especially in the recloser and sectionalizer areas. Coordination between protective equipment to improve the network reliability system so that in the event of a disturbance, the area affected by the disturbance does not spread widely. The simulation tool is made using OMRON LY2N 12V relay, ULN2803 relay driver circuit, ZMCT103C current sensor, voltage divider voltage sensor, pull down, $12 \mathrm{~V} 6 \mathrm{~W}$ lamp as a load and several resistors with different resistivity values as interference. Arduino Mega 2560 is used as the central controller for the entire circuit. After the experiment, the results obtained are when the normal network current at the recloser is $0.86 \mathrm{~A}$ and the current at the LBS SSO1 is 0.43. The recloser and LBS SSO1 coordination lies in zone 2 and 3 disturbances. When simulated zone 2 interference, the recloser current rises to $1.28 \mathrm{~A}$, causing reclose / trip to lock out recloser. When the recloser feels a fault current in zone 3 of 1.06 A and LBS SSO1 senses a current of 0.64 A. The recloser as protective equipment will open first within $1000 \mathrm{~ms}$ after sensing the disturbance. When the recloser opens, the voltage on the SSO will be 0 volts and the SSO will open within 1000 ms after the current and disturbance requirements are met. Then the recloser will close again after $2000 \mathrm{~ms}$ from the open condition.
\end{abstract}

Keywords: coordination of recloser and LBS SSO; ZMCT103C sensor; Arduino Mega 2560

\section{PENDAHULUAN}

Dalam penyaluran energi listrik ke pelanggan khususnya di Indonesia yang memiliki wilayah yang luas dan berbeda letak geografisnya membuat tantangan yang lebih besar lagi untuk pengoptimalan pendistribusian tenaga listrik karena beresiko tinggi terkena gangguan seperti gangguan yang diakibatkan pepohonan dan binatang.. Oleh karena itu PT. PLN (Persero) harus memiliki sistem proteksi tenaga listrik untuk menunjang kontinuitas dan meminimalisir daerah padam. Selain itu, sistem proteksi juga dipakai untuk melindungi peralatan dan wilayah yang penting, sehingga peralatan dan wilayah tersebut dapat terjaga dari gangguan.

Peralatan proteksi pada proses pendistribusian tenaga listrik diantaranya Pemutus Balik Otomatis (PBO) atau recloser, Saklar Seksi Otomatis (SSO) atau sectionalizier, Fuse Cute Off (FCO) dan relay proteksi. Peralatan proteksi tersebut harus tercipta koordinasi antar peralatan proteksi untuk meningkatkan sistem keandalan jaringan agar pada saat terjadi gangguan, wilayah yang terkena gangguan tersebut tidak menyebar luas.

Dalam mencapai keandalan sistem distribusi tenaga listrik dibutuhkan sistem proteksi pada sistem distribusi tenaga listrik yang baik sehingga tidak menyebabkan pemadaman meluas pada seluruh sistem. Terdapat beberapa syarat yang harus dipenuhi di dalam sistem proteksi, diantaranya [6]:

1. Kepekaan

2. Keandalan

3. Selektifitas

4. Kecepatan.
Untuk memperoleh tingkat selektifitas yang tinggi dimana hanya bagian sistem yang terganggu saja yang diisolasi (mengalami pemutusan), maka pada sistem proteksi dibentuk daerah-daerah proteksi yang dinamakan zona proteksi. Zona-zona proteksi ini biasanya dibatasi dengan PMT (CB) yang dapat memutuskan dan menghubungkan antar zona proteksi yang mengalami gangguan jika menerima instruksi dari relai [1].

Pada PT. PLN (Persero) kontrol dan otomasi yang sering digunakan pada saat ini adalah penggunaan SCADA. SCADA merupakan suatu bentuk otomasi peralatan yang banyak digunakan perusahaan industry karena SCADA memiliki fungsi monitoring dan controlling peralatan dengan jarak jauh[2].

Peran Saklar Seksi Otomatis dan Saklar Pembalik Otomatis sangatlah penting dalam sistem proteksi pendistribusian tenaga listrik. Maka dari itu dibutuhkan suatu koordinasi antar kedua peralatan tersebut seperti yang terdapat pada penyulang Kalisari 07. Dimana recloser bekerja jika merasakan arus gangguan dan menutup kembali sesuai waktu setting SSO dan recloser. Sedangkan SSO akan bekerja ketika SSO merasakan arus gangguan dan hilang tegangan.

Koordinasi yang terjadi antara SSO dan recloser yaitu ketika gangguan berada di wilayah kerja SSO, maka recloser akan open dan SSO juga akan open. Kemudian recloser akan close kembali, namun SSO masih akan tetap dalam posisi open dan akan close kembali setelah gangguan hilang atau sudah diamankan. Dalam menyimulasikan gangguan untuk menampilkan koordinasi peralatan proteksi, digunakan sebuah tahanan sebagai gangguan untuk 
menaikkan arus melebihi arus setting normal yang telah ditetapkan. Tujuan penelitian ini menyasar pada pengujian sebauh sistem monitoring untuk jaringan distribusi $20 \mathrm{KV}$ berbasis arduino dan VT SCADA, sehingga dihasilkan sebuah prototipe yang teruji secara fungsionalitas.

\section{METODE PENELITIAN}

Sistem proteksi yang ada pada jaringan distribusi $20 \mathrm{KV}$ digunakan sebagai pengaman terhadap peralatan listrik yang terpasang pada jaringan serta menjaga listrik dari kondisi abnormal sehingga listrik terus mengalir ke konsumen [7]. Kondisi abnormal yang dimaksud yaitu berupa hubung singkat (short circuit), jenis gangguan ini menyebabkan lonjakan arus yang disebut arus hubung singkat yang melalui sistem dan peralatannya. Bentuk gangguan arus hubung singkat tersebut berasal dari gangguan fasa ke tanah dan gangguan antar fasa yang sifatnya bisa temporer ataupun permanen. Oleh karena itulah, koordinasi antar peralatan perlu dilakukan untuk meningkatkan sistem keandalan jaringan agar pada saat terjadi gangguan, wilayah yang terkena dampak gangguan tidak terjadi mal trip atau black out.

Koordinasi antara recloser dengan sectionalizer bekerja berdasarkan arus gangguan untuk wilayah recloser (zona 2), sedangkan pada wilayah sectionalizer (zona 3) koordinasi dilakukan berdasar arus gangguan dan hilang tegangan.

Pada koordinasi recloser dengan sectionalizer di wilayah zona 2 dilakukan dengan arus setting ( $\mathrm{I}_{\text {setting }}$ ) pada recloser yang dibuat lebih besar dari pada arus beban pada titik recloser, dan arus setting ini harus lebih kecil dari arus total.

Menurut perhitungan pada beban, dapat dimisalkan pada alat simulasi recloser memiliki beban 1 Ampere dan memiliki arus gangguan sebesar 0,6 Ampere, sehingga arus totalnya adalah 1,6 Ampere. Dari data tersebut maka arus setting recloser pada zona 2 harus lebih dari 1 Ampere dan dibawah 1,6 Ampere (1 Ampere $<\mathrm{I}_{\text {setting }}<1,6$ Ampere)

Begitu pula pada koordinasi recloser dengan sectionalizer di wilayah zona 3 yang dilakukan berdasarkan pada arus beban di wilayah setelah sectionalizer sebesar 0,5 A, sedangkan arus gangguannya sebesar 0,25 sehingga arus totalnya menjadi 0,75 A. Maka dari itu, pada wilayah zona 3 arus setting sectionalizer harus lebih dari 0,5 A dan di bawah 0,75 Ampere $\left(0,5\right.$ Ampere $<\mathrm{I}_{\text {setting }}<0,75$ Ampere).

Pada wilayah zona 3 atau wilayah setelah sectionalizer masih termasuk wilayah kerja recloser, maka besar arus setting recloser merupakan jumlah dari beban recloser dalam keadaan normal dengan arus gangguan sectionalizer (1 Ampere + 0,25 Ampere) sama dengan 1,25 Ampere. Arus setting recloser diambil 1,1 Ampere dan setting sectionalizer diambil 0,6 Ampere. Recloser di setting trip to lock out sebanyak 3 kali.
Gambar daerah simulasi koordinasi recloser dan sectionalizer pada single line Kalisari 7 ditunjukkan pada gambar 3.1.

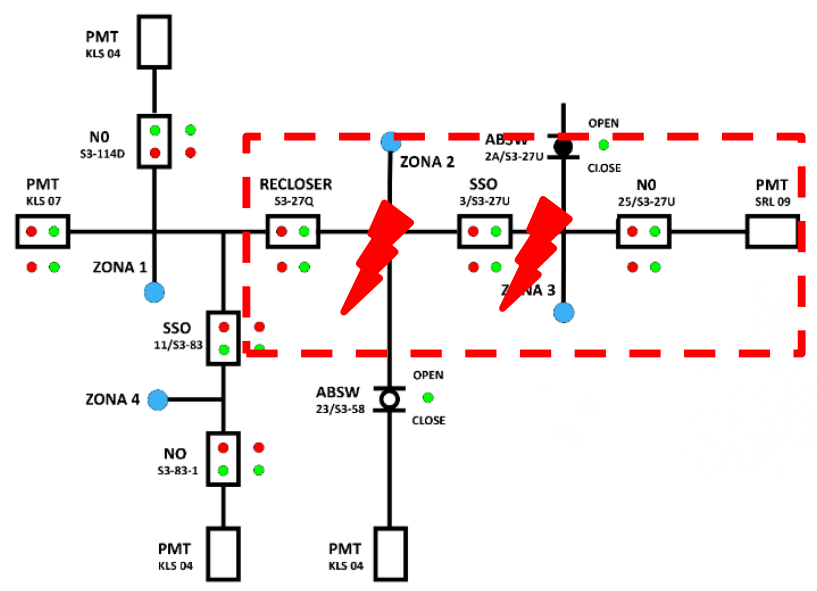

Keterangan:

Beban Recloser : 1 Ampere

Beban SSO : 0,5 Ampere

Gangguan 2 : 0,6 Ampere

Gangguan 3 : 0,25 Ampere

I setting Recloser : 1,1 Ampere

I setting SSO : 0,6 Ampere

\section{Gambar 1 Daerah Simulasi Koordinasi Recloser dan} Sectionalizer

Apabila terjadi gangguan zona 2 sehingga arus recloser melebihi settingnya dan gangguan tersebut permanen maka recloser akan trip-reclose sebanyak 2 kali dan lockout maka beban recloser dan SSO tidak teraliri arus listrik. Apabila gangguan tersebut hilang sebelum recloser reclose untuk yang kedua, maka gangguan tersebut gangguan temporer.

Apabila terjadi gangguan zona 3, SSO bekerja dengan membaca arus gangguan untuk count to open (hitungan untuk membuka) pada proteksi hulunya dan sensor tegangan tidak merasakan tegangan mengalir. Sehingga recloser akan open terlebih dahulu. Kemudian karena SSO difungsikan VIT (merasakan arus gangguan dan hilang tegangan) maka SSO berubah menjadi kondisi open. Ketika relay recloser mengalami trip, recloser akan kembali close dan beban di wilayah recloser kembali menyala.

Pada penelitian ini, penulis akan membuat simulasi koordinasi dengan sebuah penyulang dengan peralatan proteksi recloser dan sectionalizer. Kemudian pada keadaan normal, recloser dan sectionalizer akan membaca arus normal sampai rangkaian gangguan dihubungkan pada penyulang tersebut. Setelah penyulang dihubungkan dengan rangkaian gangguan, maka arus pada peralatan proteksi akan naik. Apabila kenaikan arus sudah mencapai arus setting pada peralatan proteksi, peralatan tersebut akan trip sesuai dengan koordinasi yang telah diterapkan seperti yang telah dijelaskan.

Pada perencanaan alat simulasi seperti di atas, dibagi menjadi empat section. Namun penulis 
hanya akan membahas 2 section saja yaitu section 2 dan 3. Section 2 dengan alat switching relai yang disetting reclose ketika ada gangguan berupa kenaikan arus. Section 3 dengan alat switching relai yang disetting sebagai sectionalizer.

Pada penelitian ini, penulis membuat alat yang digunakan sebagai simulator untuk menjelaskan inti materi mengenai prinsip kerja dari koordinasi recloser dan sectionalizer ketika terjadi sebuah gangguan. Peralatan yang digunakan pada simulator merupakan peralatan yang meng-implementasikan seperti sistem yang sebenarnya. Gambar blok diagram alat simulasi ditunjukkan pada gambar 2 .

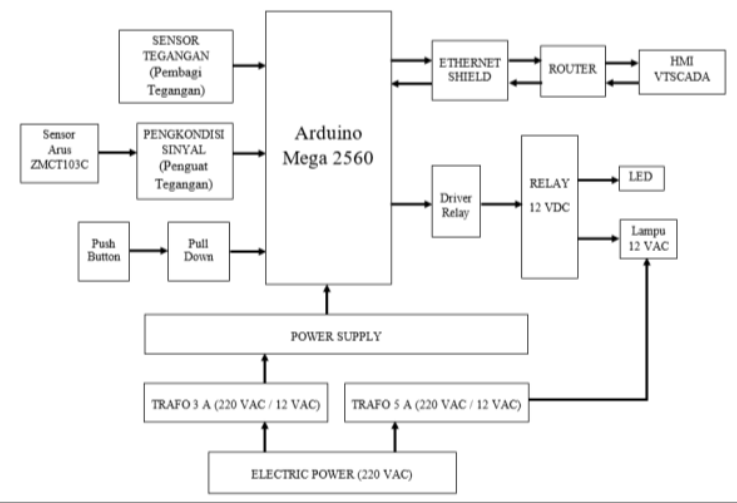

Gambar 2 Blok Diagram Alat Simulasi

Dari bagian-bagian blok diagram tersebut dapat diketaui bahwa sistem pembuatan penelitian meliputi:

1. Sumber tegangan PLN 220 VAC yang digunakan sebagai masukan transformator step-down berkapasitas 5 A.Tegangan 12 VAC ini kemudian digunakan sebagai masukan catu daya untuk disearahkan guna menyuplai lampu indikator (pilot lamp) pada rangkaian beban. Selain itu, tegangan 12 VAC juga digunakan untuk menyalakan beban lampu 12 VAC (6 Watt). Kemudian disambungkan ke sensor tegangan dan sensor arus untuk diolah di dalam mikrokontroler Arduino Mega 2560 sebelum ditampilkan pada HMI.

2. Sumber tegangan PLN 220 VAC yang digunakan sebagai masukan transformator step-down berkapasitas 3 A. Kemudian masuk ke dalam catu daya 12 VDC untuk menyuplai driver relay ULN 2803, relay 12 VDC pada recloser dan SSO, serta menyuplai Arduino Mega 2560.

3. Keluaran transformator step-down 3A yang masuk ke catu daya 12 VDC digunakan untuk menyuplai driver relay ULN 2803, lalu digunakan sebagai interface relay 12 VDC dalam mengontrol rangkaian beban dan gangguan. Outputan rangkaian beban dan gangguan tersambung dengan sensor arus dan tegangan sebelum masuk Arduino Mega 2560 yang akan ditampilkan pada HMI.

4. Sumber tegangan PLN 220 VAC yang digunakan sebagai input transformator step-down berkapasitas 3 A. Kemudian masuk ke dalam catu daya 5 VDC untuk menyuplai rangkaian push button. Keluaran push button masuk ke rangkaian pull down sebelum masuk ke pin digital Arduino Mega 2560.

5. Mikrokontroler Arduino Mega 2560 digunakan untuk menyuplai tegangan 5 VDC ke sensor arus ZMCT103C dan memberikan input berupa ground ke driver relay ULN 2803. Arduino Mega 2560 ini bertindak sebagai pusat kontrol kerja keseluruhan alat yang output-nya berupa led indikator dan kondisi high/low ke driver relay ULN 2803.

Cara kerja alat simulasi secara keseluruhan secara rimgkas dapat dilihat dari rangkaian keseluruhan yang ditunjukkan pada gambar 3 .

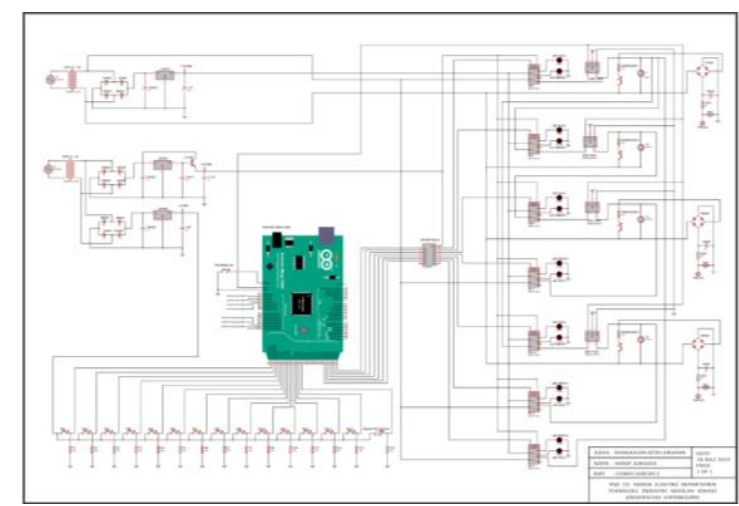

Gambar 3 Rangkaian Keseluruhan Alat Simulasi

Penjelasan dari cara kerja sisem keseluruhan ini adalah dimulai dari sumber PLN 220 volt AC yang mengalir ke transfomator linier berkapasitas 5 Ampere dan 3 Ampere yang berfungsi untuk menurunkan tegangan dari 220 VAC menjadi 12 VAC. Tegangan PLN yang mengalir melalui transformator berkapastitas 5 A berfungsi untuk menurunkan tegangan menjadi $12 \mathrm{VAC}$, yang dihubungkan dengan beban lampu pada jaringan dan catu daya 12 VDC untuk beban lampu indikator. Untuk tegangan PLN yang melalui transformator $3 \mathrm{~A}$ menurunkan tegangan menjadi 13 VAC, yang dihubungkan dengan rangkaian catu daya 12 VDC untuk menyuplai driver relay, relay OMRON LY2N, serta catu daya 5 VDC untuk menyuplai rangkaian push button pull down. Rangkaian catu daya bekerja dengan menyearahkan arus bolak-balik (AC) menjadi arus searah (DC). Penyearahan arus dari AC menjadi DC adalah hasil kerja dari 4 buah dioda yang disusun seperti rangkaian jembatan wheatstone. Keluaran dari penyearah, masih menghasilkan tegangan DC yang masih memiliki ripple. Jadi untuk menghilangkan ripple digunakan kspasitor untuk menghasilkan tegangan DC yang lebih halus[3]. Selain itu agar tegangan output stabil digunakan IC sebagai regulator tegangan. Serta perlu ditambah transistor jenis pnp tipe TIP3055 sebagai penguat arus karena beban yang akan disuplai catu daya cukup besar. Sebagai hasilnya ripple menjadi 
lebih kecil dan tegangan output DC lebih mendekati tegangan puncal 12 Volt.

Dalam keadaan saat sistem kerja alat dimulai, beban penyulang dengan lampu $12 \mathrm{AC}(6 \mathrm{~W})$ akan menyala, itu artinya recloser dan sectionalizer masih pada kondisi close. Beban pada setiap lampu dapat dikontak dengan rangkaian kontrol melalui push button, baik itu push button pada alat maupun push button pada aplikasi VTScada. Melalui push button ini kita dapat mengatur beban mana yang ingin dinyalakan atau yang dipadamkan.

Rangkaian push button dengan pull down memiliki konsep utama untuk menghilangkan floating, dimana saat keadaan push button pada rangkaian ditekan, atau dihubungkan (normally close) maka akan menghasilkan output yang bernilai high (5 volt DC), sedangkan saat keadaan terbuka (normally open) output yang dihasilkan oleh rangkaian tersebut akan bernilai low (0 volt DC)[4]. Kemudian masukan dari push button ini akan diolah melalui Arduino untuk menghidupkan atau mematikan relay. Pada penelitian ini, digunakan relay jenis DPDT (Double Pole Double Throw) merk OMRON dengan tipe LY2N.

Diagram alir dari alat simulasi ketika terdeteksi adanya gangguan ditunjukkan pada gambar 4 .

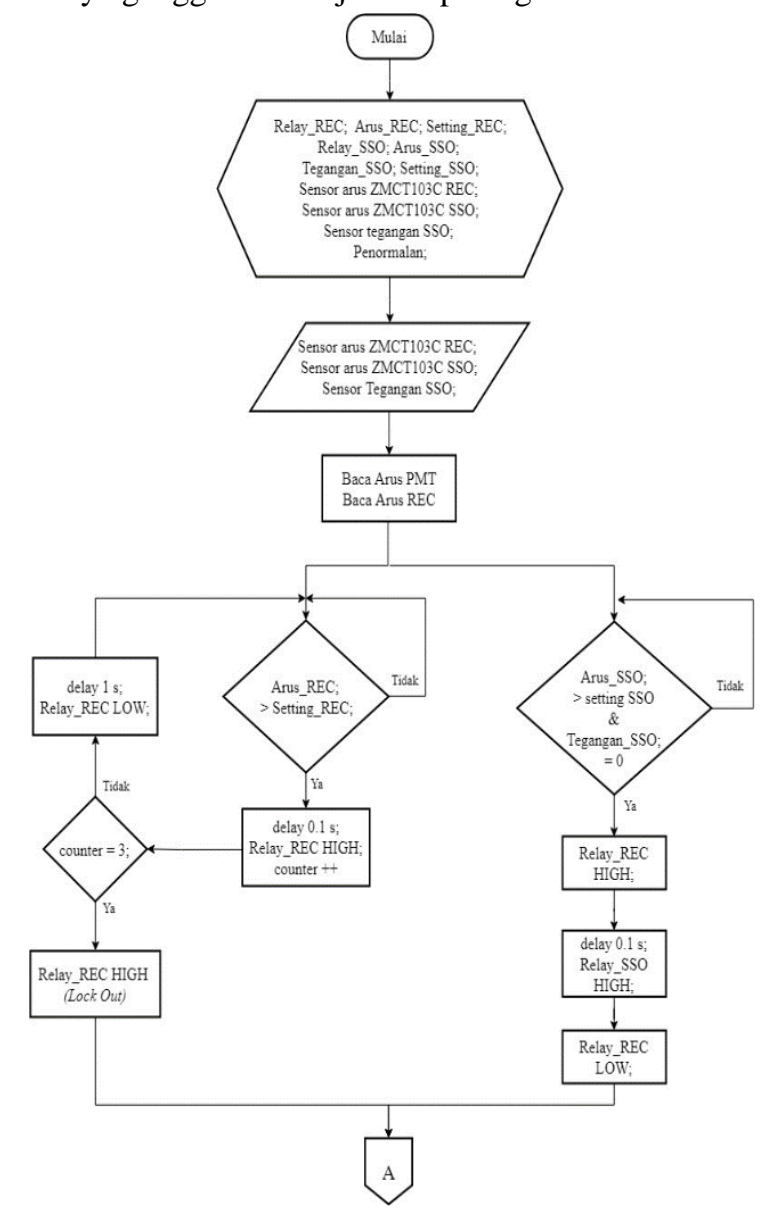

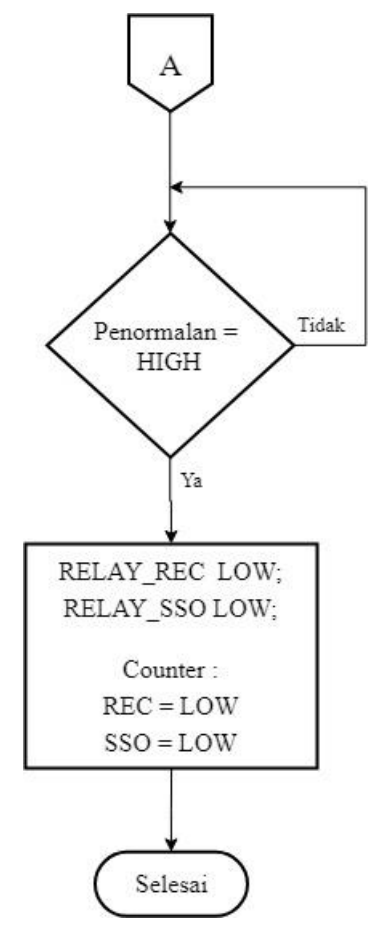

Gambar 4 Diagram Alir Saat Mendeteksi Gangguan

Dari flowchart diatas, input yang dibutuhkan adalah relay recloser, relay $\mathrm{SSO}$, sensor arus ZMCT103C untuk recloser, sensor arus ZMCT103C untuk SSO, sensor tegangan SSO, setting arus recloser, setting arus SSO, dan penormalan.

Program diawali dengan pembacaan sensor arus, kemudian pada saat arus pada recloser melebihi arus setting pada recloser maka 0,1 detik kemudian recloser akan HIGH dan counter akan bertambah menjadi 1, 1 detik kemudian recloser akan LOW atau re-close, apabila arus recloser masih melebihi arus setting pada recloser, recloser akan kembali HIGH setelah 0,1 detik dan counter bertambah lagi menjadi 2, 1 detik kemudian recloser akan LOW lagi, apabila arus pada recloser masih melebihi arus pada setting recloser maka recloser akan $\mathrm{HIGH}$ lagi dan counter bertambah menjadi 3, kemudian apabila counter bernilai 3, recloser akan lockout.

Apabila arus pada SSO melebihi arus setting pada SSO dan tegangan pada $\mathrm{SSO}=0$, maka relay recloser akan HIGH (open), selang 0,1 s kemudian relay SSO akan HIGH (open) karena merasakan arus gangguan dan hilang tegangan. Kemudian recloser akan LOW (close) karena re-close.

Setelah proses diatas selesai maka untuk memulai kembali harus ditekan tombol penormalan. Sehingga relay PMT dan relay recloser akan LOW (Close) atau normal dan counter menjadi 0.

\section{HASIL DAN PEMBAHASAN}

Pengujian dilakukan dengan menghubungkan seluruh perangkat beserta isinya, baik itu hardware dan software. . Tujuan dari percobaan alat secara keseluruhan adalah untuk mengetahui apakah kerja dari simulasi alat penelitian ini sudah dapat berfungsi 
dan sesuai dengan yang direncanakan, dimana dapat melakukan simulasi koordinasi prroteksi recloser dan LBS SSO berbasis Arduino Mega 2560 dan dapat dimonitori dengan menggunakan VT SCADA, komunikasi SCADA menggunakan Ethernet Shield yang telah disambungkan dengan Arduino Mega[5].

Pengujian alat simulasi saat dalam keadaan normal atau tanpa gangguan, karena ini merupakan hal yang pertama kali dilakukan setelah proses wiring selesei dan untuk melihat kerja alat apakah sudah sesuai dengan yang diharapkan atau belum. Hasil pengukuran ditunjukkan pada tabel 1 .

Tabel 1. Hasil Pengukuran Arus Saat Kondisi Normal

\begin{tabular}{|c|c|c|c|}
\hline $\begin{array}{l}\text { Letak } \\
\text { Sensor }\end{array}$ & Kondisi & $\begin{array}{l}\text { Pembacaan } \\
\text { Multimeter }\end{array}$ & $\begin{array}{l}\text { Pembacaan } \\
\text { Scada }\end{array}$ \\
\hline PMT & Normal & & $76 \mathrm{~A}$ \\
\hline REC & Normal & AB & $0.86 \mathrm{~A}$ \\
\hline $\begin{array}{c}\text { LBS } \\
\text { SSO } 1\end{array}$ & Normal & & $0.43 \mathrm{~A}$ \\
\hline $\begin{array}{c}\text { LBS } \\
\text { SSO } 2\end{array}$ & Normal & & 0.4 \\
\hline
\end{tabular}

Berdasarkan pada tabel 1, dapat diketahui bahwa nilai arus dari PMT sebesar 1,74 A dengan beban 4 lampu yang menyala. Arus pada Recloser dengan beban 2 lampu sebesar 0,86 A. Arus pada LBS SSO 1 dengan beban 1 lampu sebesar 0,43 A. Serta arus pada LBS SSO 2 dengan beban 1 lampu sebesar 0,44 A. . Apabila dibandingkan besar nilai arus normal recloser dan LBS SSO 1 dengan perhitungan beban secara teoritis terlihat selisih 0,14 Ampere untuk recloser dan 0,07 Ampere untuk LBS SSO 1.

Pengujian wilayah proteksi zona 2 yaitu di antara recloser dan LBS SSO 1. Saat arus yang melewati zona 2 ternyata melebihi batas setting, maka recloser akan bekerja. Gangguan yang terdapat pada zona 2 bersifat temporer, sehingga recloser akan reclose sebanyak 3 kali yang diikuti dengan recloser trip (lock out) pada kondisi akhir.

Hasil penyesuaian arus ditunjukkan pada tabel 2.

Tabel 2. Hasil Pengujian Gangguan Zona 2

\begin{tabular}{|c|c|c|c|}
\hline $\begin{array}{l}\text { Letak } \\
\text { Sensor }\end{array}$ & Kondisi & $\begin{array}{l}\text { Pembacaan } \\
\text { Multimeter }\end{array}$ & $\begin{array}{l}\text { Pembacaan } \\
\text { Scada }\end{array}$ \\
\hline REC & Normal & 178 & $1.22 \mathrm{~A}$ \\
\hline $\begin{array}{c}\text { LBS } \\
\text { SSO } 1\end{array}$ & Normal & & 0.43 \\
\hline
\end{tabular}

Dari data hasil pengujian di atas, dapat di ketahui bahwa recloser akan bekerja untuk re-close sebanyak dua kali, selama gangguan masih dirasakan maka recloser bekerja untuk re-close yang ketiga, sehingga recloser akan lock out/trip karena terjadi kenaikan nilai arus sebesar 0,42 A dimana keadaan normal 0,86 A dan saat terjadi gangguan menjadi 1,28 A. Dalam simulasi zona 2, arus SSO bisa dikatakan masih dalam kondisi normal karena hanya berubah 0,02 A saja jadi tidak membuat SSO berubah posisi menjadi open.

Jika dilihat dengan perhitungan secara teoritis nilai arus pada recloser ketika terdeteksi gangguan adalah 1,6 Ampere, sedangkan saat pengujian alat simulasi nilai arus recloser saat terdeteksi gangguan hanya sebesar 1,28 Ampere. Sehingga apabila dibandingkan muncul selisih nilai arus sebesar 0,32 Ampere.

Pengujian yang ketiga dilakukan pada wilayah proteksi zona 3.Apabila arus yang terdapat pada zona 3 ini melebihi batas setting yaitu 0,43 A, maka LBS SSO 1 bekerja dengan membaca arus gangguan dan proteksi hulunya akan membuka serta sensor tegangan tidak merasakan tegangan mengalir, Sehingga beban yang ada di recloser dan LBS SSO 1 akan padam, namun setelah LBS SSO 1 berubah menjadi normally open maka recloser akan otomatis menutup kembali (re-close) dan beban di wilayah recloser pun akan kembali menyala.

Hasil dari pengujia saat terdapat gangguan di zona 3 akan disajikan dalam tabel di bawah ini.

Tabel 3. Hasil Pengujian Gangguan Zona 3

\begin{tabular}{|c|c|c|c|}
\hline $\begin{array}{l}\text { Letak } \\
\text { Sensor }\end{array}$ & Kondisi & $\begin{array}{l}\text { Pembacaan } \\
\text { Multimeter }\end{array}$ & $\begin{array}{l}\text { Pembacaan } \\
\text { Scada }\end{array}$ \\
\hline REC & Normal & iith & $1.03 \mathrm{~A}$ \\
\hline $\begin{array}{c}\text { LBS } \\
\text { SSO } 1\end{array}$ & Normal & & 0.6 \\
\hline
\end{tabular}

Dari data hasil pengujian di atas, dapat diketahui bahwa ketika terdapat gangguan pada zona 3, setting arus LBS SSO 1 akan naik menjadi 0,64 A dan setting arus recloser pun juga akan naik menjadi $1,06 \mathrm{~A}$.

Jika dilihat dengan perhitungan secara teoritis nilai arus pada LBS SSO 1 ketika terdeteksi gangguan adalah 0,75 Ampere, sedangkan saat pengujian alat simulasi nilai arus recloser saat terdeteksi gangguan hanya sebesar 0,64 Ampere. Sehingga apabila dibandingkan muncul selisih nilai arus sebesar 0,11 Ampere. 


\section{KESIMPULAN}

Ketika terjadi gangguan pada ona 2 recloser bekerja bekerja untuk re-close sebanyak dua kali, selama gangguan masih dirasakan maka recloser bekerja untuk re-close yang ketiga, sehingga recloser akan lock out/trip. Ketika terjadi gangguan pada zona 3 yang menyebabkan beban pada zona 2 dan 3 padam, recloser yang awalnya membuka akan re-close sehingga hanya LBS SSO 1 saja yang berubah menjadi open Karena merasakan arus gangguan dan hilang tegangan.

Sensor arus yang digunakan sebagai pengganti Trafo Arus (CT) pada alat simulasi ini adalah ZMCT103C. Dalam simulasi ini dibutuhkan dua buah untuk menyimulasikan gangguan di wilayah kerja recloser dan LBS SSO 1. Pada kondisi normal arus pada recloser 0,86 A dan pada LBS SSO $10,43 \mathrm{~A}$. Saat terjadi gangguan zona 2 arus recloser naik menjadi $1,28 \mathrm{~A}$, sedangkan saat terjadi gangguan zona 3 arus LBS SSO 1 naik menjadi 1,06 A dan LBS SSO 1 menjadi 0,64 A.

Sensor tegangan berupa pembagi tegangan bekerja mendeteksi tegangan pada LBS SSO1 saat kondisi normal maupun saat terdapat gangguan pada Zona 2 dan Zona 3. Dimana saat kondisi normal tegangan yang terukur 11,09 VAC.

Pada simulator ini, sistem monitoring berbasis VT Scada dapat digunakan sebagai monitoring beban pelanggan Penyulang Kalisari 7 dan saat terindikasi gangguan. Sistem controlling keypoint berbasis VT Scada digunakan untuk memudahkan saat dilakukan proses manuver dan penormalan pada peralatan yang terdapat pada keypoint dari jarak jauh.

Pada saat pengujian simulasi gangguan di Zona 2, arus recloser naik 0,42 A. Dari kenaikan arus pada recloser, menyebabkan recloser reclose/trip to lock out karena melewati dari batas setting arus recloser sebesar 1,1 A, sebab arus naik menjadi 1,28 A. Dikarenakan LBS SSO1 merasakan hilang tegangan maka beban di wiayah LBS SSO1 pun ikut padam namun masih dalam posisi close. Dari pengujian yang dilakukan muncul perbedaan nilai arus yang dibandingkan dengan perhitungan teoritis sebesar 0,32 Ampere.

Saat pengujian koordinasi recloser dan LBS SSO1 pada gangguan Zona 3 arus recloser dan LBS SSO 1 naik sebesar 0,2 A dari kondisi normal. Sehingga recloser sebagai peralatan proteksi akan open terlebih dahulu dalam waktu 1000 ms setelah merasakan gangguan. Ketika recloser open, maka tegangan pada SSO akan bernilai 0 volt dan SSO akan open dalam waktu $1000 \mathrm{~ms}$ setelah syarat arus dan ganguan terpenuhi. Kemudian recloser akan close kembali setelah $2000 \mathrm{~ms}$ dari kondisi open. Dari pengujian koordinasi wilayah zona 3 muncul perbedaan nilai arus yang dibandingkan dengan perhitungan teoritis sebesar 0,11 Ampere.

\section{UCAPAN TERIMAKASIH}

Terimasih kepada Sekolah Vokasi Universitas Diponegoro, dosen dan petugas laboratorium PSDIII Teknik Elektro dan Supervisor PT. PLN UP2D Jateng \& DIY beserta jajarannya yang sangat membantu dalam pengumpulan data sehingga penelitian ini dapat terlaksana.

\section{DAFTAR PUSTAKA}

[1] Saputra, Rian Adhi. 2009. Studi Analisa Koordinasi Sectionalizer Recloser Menggunakan Metode RIA Untuk Peningkatan Keandalan Pada Penyulang Suparma II Di GI Waru. Laporan Penelitian Tidak Diterbitkan. Surabaya: Institut Teknologi Sepuluh Nopember.

[2] Pandjaitan, Bonar. 1999. Teknologi Sistem Pengendalian Tenaga Listrik Berbasis Scada. Jakarta: SMTG Desa Putera.

[3] Widodo, Sri Thomas. 2002. Elektronika Dasar. Jakarta: Salemba Teknik

[4] Embenesia, 2015. Pull Up dan Pull Down. https://embenesia.wordpress.com/.Diakses tanggal 21 juni 2019 pukul 21.03.

[ 5 ] Arduino \& Genuino Products. Getting Started with the Arduino Ethernet Shield. https://www.arduino.cc/en/Guide/ArduinoEthe rnetShield. Diakses tanggal 30 Juni 2019 pukul 21.37.

[6] O. Cwikowski, M. Barnes, R. Shuttleworth, and B. Chang, Analysis and simulation of the proactive hybrid circuit breaker, in Proceedings of the International Conference on Power Electronics and Drive Systems, 2015.

[ 7 ] M. Darwish, C. Marouchos, and P. Dimitriadis, Overvoltage protection, in Proceedings 2016 51st International Universities Power Engineering Conference, UPEC 2016, 2017. 